\title{
Metabolome profiling in skeletal muscle to characterize metabolic alterations in over-conditioned cows during the periparturient period
}

\author{
H. Sadri, ${ }^{1 *}$ M. H. Ghaffari, ${ }^{2}$ K. Schuh,,${ }^{2,3}$ G. Dusel, ${ }^{3}$ C. Koch, ${ }^{4}$ C. Prehn, ${ }^{4}$ J. Adamski, ${ }^{5,6,7}$ and H. Sauerwein ${ }^{2} \dagger$ \\ ${ }^{1}$ Department of Clinical Science, Faculty of Veterinary Medicine, University of Tabriz, 516616471 Tabriz, Iran \\ ${ }^{2}$ Institute of Animal Science, Physiology and Hygiene Unit, University of Bonn, 53115 Bonn, Germany \\ ${ }^{3}$ Department of Life Sciences and Engineering, Animal Nutrition and Hygiene Unit, University of Applied Sciences Bingen, \\ 55411 Bingen am Rhein, Germany \\ ${ }^{4}$ Educational and Research Center for Animal Husbandry, Hofgut Neumuehle, 67728 Muenchweiler an der Alsenz, Germany \\ ${ }^{5}$ Research Unit Molecular Endocrinology and Metabolism, Genome Analysis Center, Helmholtz Zentrum München, \\ German Research Center for Environmental Health, Neuherberg, Germany 85764 \\ ${ }^{6}$ Lehrstuhl für Experimentelle Genetik, Technische Universität München, Freising-Weihenstephan 85350, Germany \\ ${ }^{7}$ Department of Biochemistry, Yong Loo Lin School of Medicine, National University of Singapore, 8 Medical Drive, Singapore 117597, Singapore
}

\begin{abstract}
The transition from late gestation to early lactation is associated with extensive changes in metabolic, endocrine, and immune functions in dairy cows. Skeletal muscle plays an important role in maintaining the homeorhetic adaptation to the metabolic needs of lactation. The objective of this study was to characterize the skeletal muscle metabolome in the context of the metabolic changes that occur during the transition period in dairy cows with high (HBCS) versus normal body condition (NBCS). Fifteen weeks antepartum, 38 pregnant multiparous Holstein cows were assigned to 1 of 2 groups, which were fed differently to reach the targeted BCS and back fat thickness (BFT) until dry-off at $-49 \mathrm{~d}$ before calving (HBCS: $>3.75$ and $>1.4 \mathrm{~cm}$; NBCS: $<3.5$ and $<1.2 \mathrm{~cm}$ ). During the dry period and the subsequent lactation, both groups were fed identical diets. The differences in both BCS and BFT were maintained throughout the study. The metabolome was characterized in skeletal muscle samples (semitendinosus muscle) collected on $\mathrm{d}-49,3,21$, and 84 relative to calving using a targeted metabolomics approach (AbsoluteIDQ p180 kit; Biocrates Life Sciences AG, Innsbruck, Austria), which allowed for the quantification of up to 188 metabolites from 6 different compound classes (acylcarnitines, amino acids, biogenic amines, glycerophospholipids, sphingolipids, and hexoses). On d -49 , the concentrations of citrulline and hydroxytetradecadienyl-L-carnitine in muscle were
\end{abstract}

Received September 9, 2019.

Accepted November 28, 2019

*H. Sadri was a visiting scientist at the Institute of Animal Science, Physiology and Hygiene Unit, University of Bonn, 53115 Bonn, Germany at the time the research was done.

†Corresponding author: sauerwein@uni-bonn.de higher in HBCS cows than in NBCS cows, but those of carnosine were lower. Over-conditioning did not affect the muscle concentrations of any of the metabolites on d 3. On d 21, the concentrations of phenylethylamine and linoleylcarnitine in muscle were lower in HBCS cows than in NBCS cows, and the opposite was true for lysophosphatidylcholine acyl C20:4. On d 84, the significantly changed metabolites were mainly long-chain (>C32) acyl-alkyl phosphatidylcholine and di-acyl phosphatidylcholine, along with 3 long-chain (>C16) sphingomyelin that were all lower in HBCS cows than in NBCS cows. These data contribute to a better understanding of the metabolic adaptation in skeletal muscle of dairy cows during the transition period, although the physiological significance and underlying molecular mechanisms responsible for the regulation of citrulline, hydroxytetradecadienyl-L-carnitine, carnosine, and phenylethylamine associated with over-conditioning are still elusive and warrant further investigation. The changes observed in muscle lysophosphatidylcholine and phosphatidylcholine concentrations may point to an alteration in phosphatidylcholine metabolism, probably resulting in an increase in membrane stiffness, which may lead to abnormalities in insulin signaling in the muscle of over-conditioned cows.

Key words: muscle, targeted metabolomics, body condition score (BCS), transition cow

\section{INTRODUCTION}

In the dairy cow, late gestation and early lactation are associated with comprehensive physiological and metabolic changes (Drackley, 1999). Voluntary feed intake begins to decrease during the last weeks of pregnancy until parturition, and increases more slowly than milk yield during the postpartum period (Hayirli et al., 2002; Kuhla et al., 2011). As a consequence, 
high-yielding dairy cows experience negative nutrient balance, which may be associated with metabolic disorders, compromised immune and reproductive function, and reduced lactation performance (Drackley, 1999). To accomplish increasing milk yields in spite of insufficient feed intake, body reserves - including fat, protein, and glycogen - need to be mobilized (Ingvartsen and Andersen, 2000). The bulk of the mobilized protein appears to be derived from peripheral tissues, especially skeletal muscle and, to a lesser extent, skin (Meijer et al., 1995), mediated by the suppression of tissue protein synthesis and probably increased proteolysis (Bell et al., 2000; Chibisa et al., 2008). Thus, skeletal muscle, the largest internal organ in mammals, plays a major role in maintaining metabolic homeostasis and adaptation to the physiological needs of pregnancy and lactation. However, unlike in liver and adipose tissue, the metabolic and regulatory role of skeletal muscle in the adaptation of dairy cows to early lactation has not been studied extensively.

Body condition score at calving is among the most important factors affecting early lactation DMI (Garnsworthy and Jones, 1987; Roche et al., 2008), postpartum BCS loss (Roche et al., 2007a; Gärtner et al., 2019), lactation performance (Berry et al., 2007; Roche et al., 2007b), reproduction (Buckley et al., 2003), and periparturient metabolic disorders (Gillund et al., 2001; Roche and Berry, 2006) in dairy cows. Overconditioned cows are more likely to have difficulties at and after calving as a result of suboptimal transition from pregnancy to lactation and such difficulties may lead to substantial economic losses. Results reported on performance and metabolic changes as part of this experiment (Schuh et al., 2019) demonstrated that cows calving with a high BCS were metabolically challenged during early lactation because of a more severe negative energy balance and intense mobilization of body fat associated with reduced early lactation DMI and compromised antioxidative capacity.

The metabolome (representing the terminal downstream product of the genome, transcriptome, and proteome) and the development of sophisticated bioinformatics tools have been valuable in unraveling the complexity and specificity of metabolic changes in a particular condition. Interest is also increasing in metabolomic profiling for the identification of novel biomarkers to predict the risk of diseases (Zhang et al., 2017b; Dervishi et al., 2018) or pathway discovery in some metabolic diseases in dairy cows during the periparturient period (Hailemariam et al., 2014; Zhang et al., 2017a; Zandkarimi et al., 2018). The involvement of skeletal muscle protein, glycogen, and fat metabolism in the adaptation to early lactation assessed by AA profiling and proteome analysis has been reported in dairy cows (Kuhla et al., 2011). However, the actual alterations in the muscle metabolome associated with over-conditioning throughout the transition period in dairy cows are not yet clearly understood. Identification of specific metabolomic "signatures" associated with over-conditioning is of utmost importance to help to fill gaps in knowledge related to how metabolic homeostasis might be perturbed during the periparturient period. Our previous study in dairy cows in the medium BCS range suggests that the ability to complete fatty acid (FA) oxidation in the skeletal muscle around parturition decreases, likely due to insufficient metabolic adaptation in response to a load of FA (Yang et al., 2019). In the current study, we hypothesized that an in-depth metabolomic analysis of skeletal muscle would reveal dynamic markers of key regulatory metabolic intermediates, primarily belonging to the muscle lipidome, and would reflect changes in oxidative capacity in the skeletal muscle around calving that are associated with BCS at calving and BCS loss postpartum.

\section{MATERIALS AND METHODS}

\section{Animals, Management, and Treatments}

The experiment was conducted at the Educational and Research Center for Animal Husbandry, Hofgut Neumuehle, Muenchweiler a.d. Alsenz, Germany. The experimental procedures performed in this study were in accordance with the European Union Guidelines concerning the protection of experimental animals, with approval by the local authority for animal welfare affairs (Landesuntersuchungsamt Rheinland-Pfalz, Koblenz, Germany; G 14-20-071). The animals were part of a trial aiming to establish an experimental model of high versus normal body reserve mobilization around calving. The basic setup of the trial, together with performance data, has already been reported (Schuh et al., 2019). In brief, 15 wk before calving, 38 multiparous German Holstein cows (average parity $2.9 \pm 0.3$; mean \pm standard error of the mean) were allocated to a normal-conditioned (NBCS; $\mathrm{n}=19$ ) or a high-conditioned group (HBCS; $\mathrm{n}=19$ ). To reach the targeted differences in BCS and back fat thickness $($ BFT) in the experimental groups (NBCS: BCS $<3.5$ and $\mathrm{BFT}<1.2 \mathrm{~cm}$; HBCS: $\mathrm{BCS}>3.75$ and $\mathrm{BFT}>1.4$ $\mathrm{cm})$ until dry-off (wk 7 antepartum), NBCS cows received a low-energy ration (6.8 MJ of $\mathrm{NE}_{\mathrm{L}} / \mathrm{kg}$ of $\mathrm{DM}$ ), and HBCS cows received a high-energy ration (7.2 MJ of $\mathrm{NE}_{\mathrm{L}} / \mathrm{kg}$ of $\mathrm{DM}$ ) during late lactation (from wk 15 to 7 before the anticipated calving date). An overview of the experimental setup used in this study is given in Figure 1A. During the dry period and subsequent lactation, both groups received identical diets. The 
diets were fed as TMR for ad libitum intake, consisting of $63 \%$ roughage and $37 \%$ concentrate in the highenergy diet, or $74 \%$ roughage and $26 \%$ concentrate in the low-energy diet. The diets were formulated to meet the nutritional requirements of Holstein cows according to the recommendations of the Society of Nutrition Physiology (GfE, 2001). A detailed description of the ingredients, as well as the composition of the diets, is given in Supplemental Table S1 (https://doi.org/10 $.3168 /$ jds.2019-17566).

During the experimental period (15 wk antepartum until 15 wk postpartum), BCS and BFT were monitored biweekly by the same person. Body condition score was assessed using a 5-point scale (Edmonson et al., 1989), and BFT was assessed in the sacral region using ultrasonography (Agroscan L, ALR 500, 5

(A)

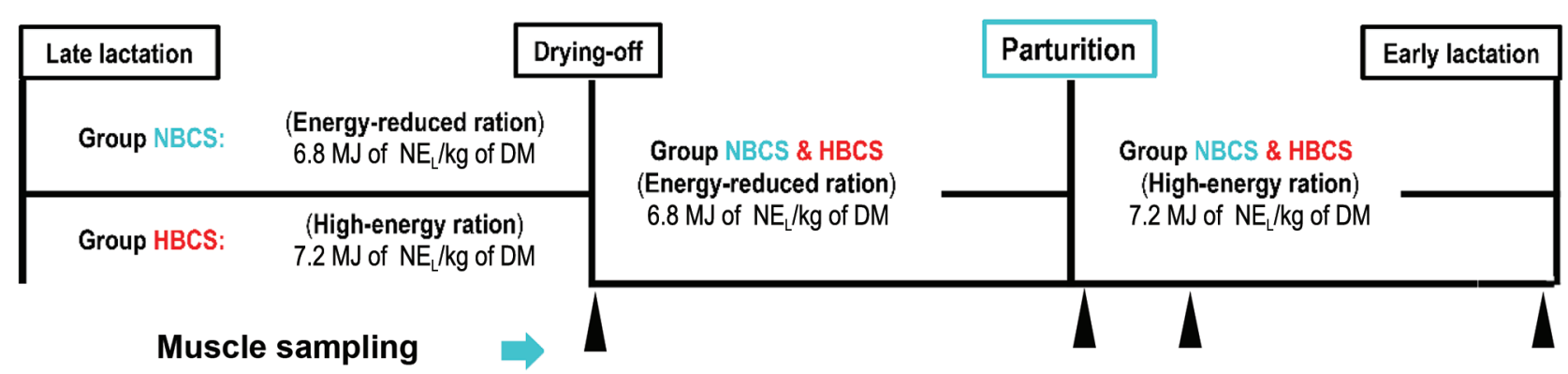

Day 49 a.p.

Day 3 p.p. Day 21 p.p.

Day 84 p.p.

NBCS $\square$ HBCS

(B)

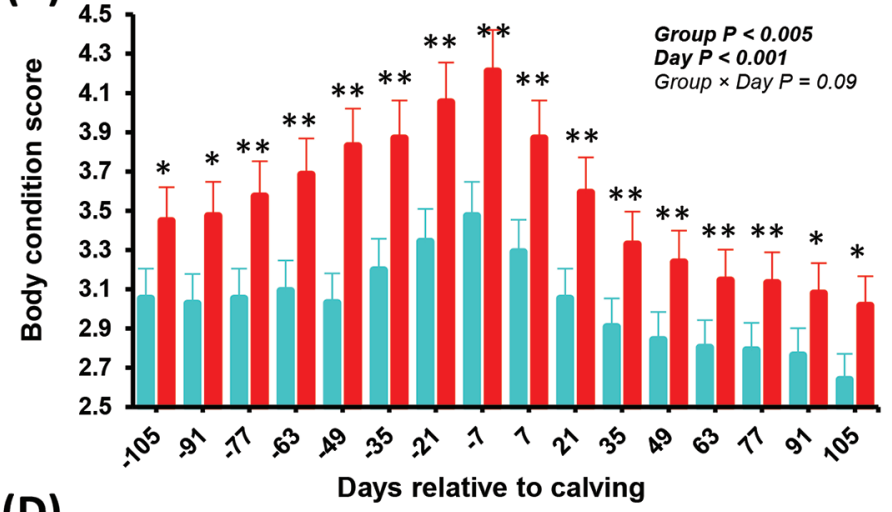

(D)

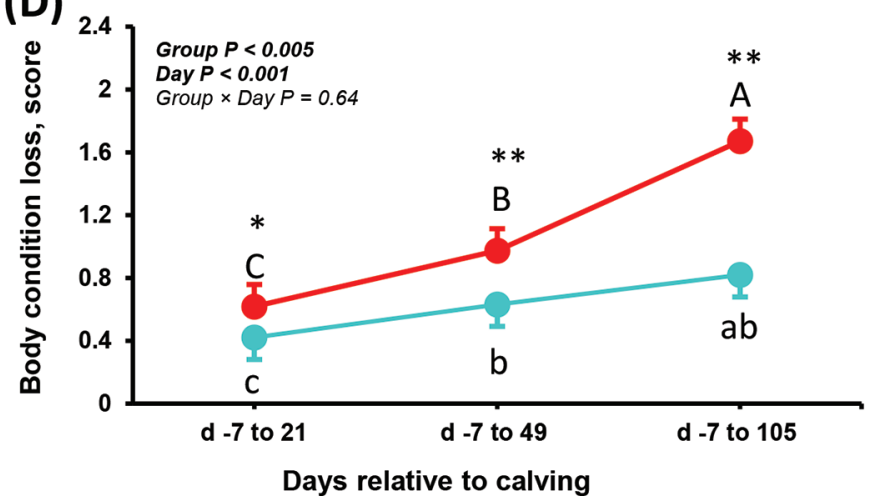

(C)

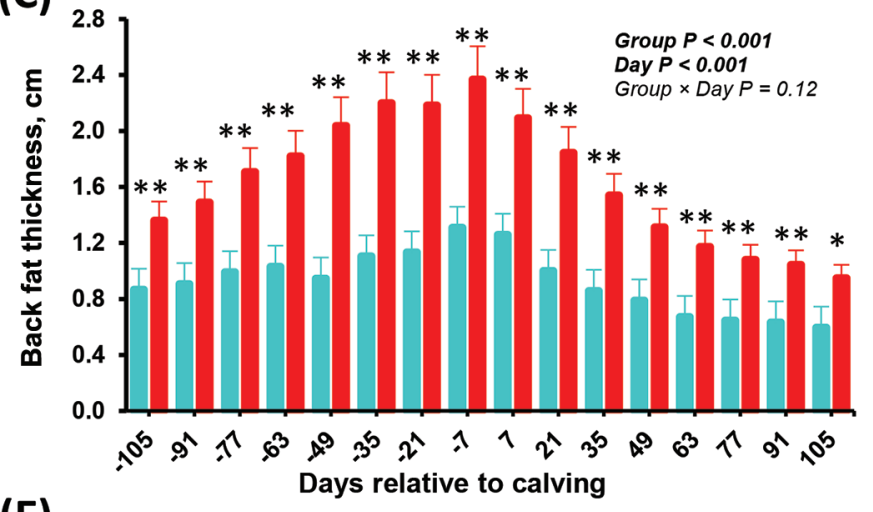

(E)

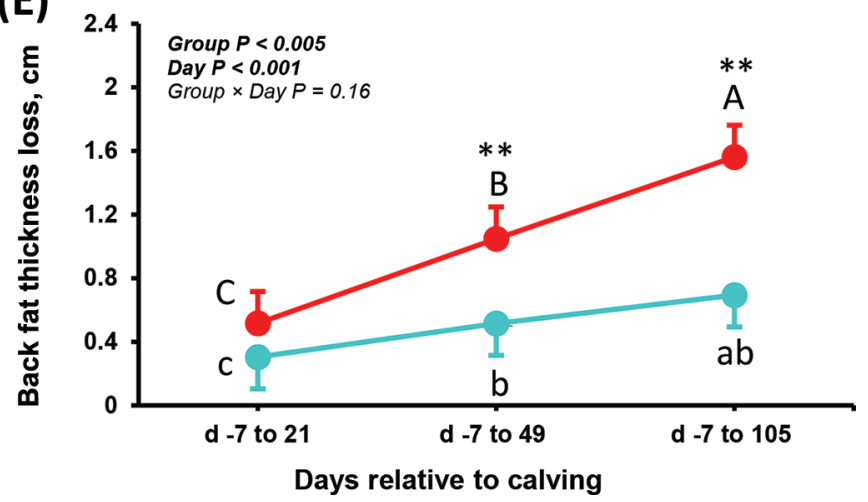

Figure 1. (A) Scheme of the experimental protocol. Changes in (B) BCS, (C) back fat thickness, (D) body condition loss, and (E) back fat thickness loss in normal-conditioned (NBCS) and high-conditioned (HBCS) cows during the experimental period. Symbols indicate significant differences $\left({ }^{*} P<0.05 ;{ }^{*} P<0.01\right)$ between the groups at a given time point. Different uppercase letters $(\mathrm{A}-\mathrm{C})$ indicate differences between time points within HBCS cows, and different lowercase letters $(\mathrm{a}-\mathrm{c})$ indicate differences between time points within NBCS cows. Data for BCS, back fat thickness, body condition loss, and back fat thickness loss are from Schuh et al. (2019). Data are presented as mean \pm SEM. a.p. $=$ antepartum; p.p. = postpartum. 
$\mathrm{MHz}$, linear-array transducer; Echo Control Medical, Angoulême, France).

\section{Sampling and Laboratory Analyses}

Biopsies from the semitendinosus muscle were collected at $\mathrm{d}-49( \pm 5), 3( \pm 2), 21( \pm 2)$, and $84( \pm 2)$ relative to calving under local anesthesia (procaine hydrochloride, $20 \mathrm{mg} / \mathrm{mL}, 8 \mathrm{~mL}$ per biopsy; Richter Pharma AG, Wels, Austria), and while the animals were sedated (xylazine i.v., $20 \mathrm{mg} / \mathrm{mL}, 0.1 \mathrm{~mL} / 100 \mathrm{~kg}$ BW; CP-Pharma Handels GmbH, Burgdorf, Germany) and fixed in a headlock. Muscle samples were collected through a $1 \mathrm{~cm}$ incision using a Bard Magnum biopsy instrument and Bard Magnum core tissue biopsy needles (12 gauge $\times 20 \mathrm{~cm}$; C.R. Bard Inc., Tempe, AZ). After tissue extraction, oxytetracycline hydrochloride was applied to the skin to prevent infection (25 $\mathrm{mg} / \mathrm{mL}$, Engemycin; MSD Animal Health Innovation GmbH, Schwabenheim an der Selz, Germany) and a ketoprofen injection $(100 \mathrm{mg} / \mathrm{mL}, 3 \mathrm{~mL} / 100 \mathrm{~kg}$ BW; Streuli Pharma AG, Uznach, Germany) was given to prevent pain. Tissue samples were rinsed with $0.9 \%$ $\mathrm{NaCl}$ to remove any blood contamination, immediately snap-frozen in liquid nitrogen, and stored at $-80^{\circ} \mathrm{C}$ until analysis.

The metabolome was characterized in muscle samples using a targeted quantitative metabolomics approach and a commercially available kit (AbsoluteIDQ p180 kit; Biocrates Life Sciences AG, Innsbruck, Austria). The metabolite panel consists of 188 different metabolites, including $21 \mathrm{AA}, 40$ acylcarnitines, 15 sphingomyelins, 90 glycerophospholipids, 21 biogenic amines, and hexoses. The complete list of metabolites is given in Supplemental Table S2 (https://doi.org/10.3168/ jds.2019-17566). The abbreviations, written as Cx:y, are used to describe the total number of carbons and double bonds of all chains, respectively. Sample preparation and analysis were performed in the Helmholtz Zentrum München (GmbH), German Research Center for Environmental Health, Genome Analysis Center (Munich, Germany). In brief, $25 \mathrm{mg}$ of frozen samples were homogenized and extracted using homogenization tubes with ceramic beads $(1.4 \mathrm{~mm})$ and a Precellys 24 homogenizer with an integrated cooling unit (PEQLAB Biotechnology GmbH, Darmstadt, Germany). Then, 3 $\mu \mathrm{L}$ of a dry-ice-cooled mixture of ethanol/phosphate buffer $(85 / 15, \mathrm{vol} / \mathrm{vol})$ were added per milligram of frozen muscle tissue. Following centrifugation, $10 \mu \mathrm{L}$ of the homogenate supernatant were added to the well plate of the AbsoluteIDQ p180 kit. The assay procedures of the kit, a detailed description of the tissue preparation, and metabolite nomenclature are described in detail elsewhere (Zukunft et al., 2013, 2018). Sample handling was performed using a Hamilton Microlab STAR robot (Hamilton Bonaduz AG, Bonaduz, Switzerland) and an Ultravap nitrogen evaporator (Porvair Sciences, Leatherhead, UK), along with standard laboratory equipment. Mass spectrometric analyses were performed on an API 4000 triple quadrupole system (Sciex Deutschland $\mathrm{GmbH}$, Darmstadt, Germany) equipped with a 1200 Series HPLC (Agilent Technologies Deutschland GmbH, Böblingen, Germany) and an HTC PAL auto sampler (CTC Analytics, Zwingen, Switzerland) controlled by Analyst 1.6.1 software. Data evaluation for quantification of metabolite concentrations and quality assessment was performed using the MetIDQ software package, which is an integral part of the AbsoluteIDQ p180 kit. Internal standards were used as a reference to calculate the concentrations of the metabolites. The concentrations in muscle tissue samples were given in picomoles per milligram of tissue, and the concentrations of tissue homogenate in micromoles per liter.

\section{Statistical Analyses}

Statistical analysis of the muscle metabolite data was performed using the web-based metabolomics data processing tool MetaboAnalyst 4.0 (Chong et al., 2018). Briefly, as a quality control, variables containing more than $50 \%$ missing values (i.e., values lower than the limit of detection) were not considered for statistical analysis. The metabolite data were transformed using generalized log-transformation and then Pareto-scaled to correct for heteroscedasticity, to reduce the skewness of the data, and to reduce mask effects (van den Berg et al., 2006). Volcano plots were created to provide an overview of the significantly affected metabolites. Volcano plots are used to relate fold change to statistical significance. Important metabolites were selected by volcano plot based on a fold-change threshold of 1.3 on the $\mathrm{x}$-axis and a $t$ test threshold ( $P$-value) of 0.1 on the $y$-axis. The data for muscle metabolites identified by volcano plot were then analyzed using estimation methods and presented as mean difference estimation plots (Claridge-Chang and Assam, 2016). Effect size was measured using Hedges' $g$ (Greenland et al., 2016) and were referred to as trivial $(g<0.2)$, small $(0.2<$ $g<0.5)$, moderate $(0.5<g<0.8)$, or large $(g>0.8)$, as per standard practice. The effect size was presented as a bootstrap $95 \%$ confidence interval on separate but aligned axes. To indicate estimate precision, 95\% confidence intervals for mean differences were calculated using bootstrap methods (resampled 5,000 times, biascorrected, and accelerated) and are displayed with the bootstrap distribution of the mean. The Mann-Whitney U test was used to calculate $P$-values for pro forma reporting exclusively (Crichton, 2000). 
The data were also analyzed using the MIXED procedure in SAS (version 9.4; SAS Institute Inc., Cary, NC), with repeated measures followed by Tukey's honestly significant difference test to identify metabolites that differed significantly across the time course, regardless of treatment. The model consisted of time (day relative to calving) as a fixed effect and cow as a random effect. An autoregressive (order 1) covariance structure was chosen based on the Akaike and Bayesian information criteria. The threshold of significance was set at $P \leq$ 0.05 ; trends were declared at $0.05<P \leq 0.10$.

\section{RESULTS}

\section{Body Condition and BFT}

A more detailed description of variables characterizing body condition, BFT, and animal performance is given in Schuh et al. (2019). In brief, both BCS and BFT differed between the 2 treatment groups throughout the study period: HBCS cows had higher values than NBCS cows (both $P<0.01$; Figure 1B-C). With the onset of lactation, BCS and BFT decreased in both groups; the declines until wk 15 postpartum were greater for HBCS cows than for NBCS cows $(P<$ 0.005; Figure 1D-E).

\section{Muscle Metabolome Profiles}

We performed univariate analysis with a volcano plot to obtain a preliminary overview of the metabolites that contributed most significantly to differentiating between the 2 groups. Figures 2, 3, and 4 show the significant metabolites identified by volcano plot on $\mathrm{d}-49,21$, and 84, respectively. As shown in Supplemental Figure S1 (https://doi.org/10.3168/jds.2019 -17566), we observed no significant differences between HBCS and NBC cows on d 3 for muscle concentrations of any metabolites. The volcano plots illustrate the relationship between the $P$-values of the statistical test and the magnitude of the difference in concentrations between the treatment groups.

The muscle concentrations of citrulline (effect size, $g=0.905 ; P=0.05)$ and hydroxytetradecadienylL-carnitine (C14:2-OH; $g=0.934 ; P=0.02)$ were greater in HBCS cows than in NBCS cows on $\mathrm{d}-49$ (Figure 2C-D), whereas those of carnosine $(g=-0.65$; $P=0.05$ ) were lower (Figure $2 \mathrm{~B}$ ). On d 21, the muscle concentrations of phenylethylamine (PEA; $g=-1.1$; $P=0.002)$ and octadecadienylcarnitine (C18:2; $g=$ $-0.57 ; P=0.01)$ were lower in HBCS cows than in NBCS cows (Figure 3B-C), whereas those of lysophosphatidylcholine acyl (lysoPC a) C20:4 $(g=0.511 ; P$ $=0.05$ ) showed a reverse change (Figure 3D). On d 84, the muscle concentrations of phosphatidylcholine acylalkyl (PC ae) C34:3 $(g=-0.755 ; P=0.03), \mathrm{C} 36: 3(g$ $=-0.956 ; P=0.007)$, C36:4 $(g=-0.91 ; P=0.02)$, C36:5 $(g=-0.816 ; P=0.02), \mathrm{C} 38: 3(g=-1.23 ; P=$ $0.01)$, C $38: 4(g=-1.21 ; P=0.001)$, C $38: 5(g=-1.17$; $P=0.001)$, C38:6 $(g=-1.06 ; P=0.01), \mathrm{C} 40: 4(g=$ $-1.17 ; P=0.001), \mathrm{C} 40: 5(g=-1.46 ; P=0.0003)$, and $\mathrm{C} 40: 6(g=-0.57 ; P=0.01)$, as well as phosphatidylcholine di-acyl (PC aa) C32:3 $(g=-0.789$; $P=0.01), \mathrm{C} 34: 4(g=-1.17 ; P=0.002), \mathrm{C} 36: 0(g=$ $0.87 ; P=0.01)$, C36:6 $(g=-1.19 ; P=0.003)$, C38:0 $(g=-1.32 ; P=0.0002), \mathrm{C} 38: 4(g=-0.493 ; P=$ $0.07), \mathrm{C} 42: 4(g=-0.725 ; P=0.04)$, and $\mathrm{C} 43: 3(g=$ $-0.784 ; P=0.06)$, were lower or tended to be lower in HBCS cows than in NBCS cows (Figure 4). The muscle concentrations of methionine $(g=-0.732 ; P=0.02)$, methioninesulfoxide (Met-SO; $g=-0.688 ; P=0.05$ ), sphingomyelin (SM) C18:0 $(g=-0.714 ; P=0.05), \mathrm{SM}$ $(\mathrm{OH}) \mathrm{C} 16: 1(g=-1.27 ; P=0.001)$, valerylcarnitine ( $g=0.54 ; P=0.06)$, and hydroxyisovalerylcarnitine/ hydroxy-2-methylbutyryl/hydroxyvalerylcarnitine $(g=$ $-0.706 ; P=0.01)$ on d 84 were lower or tended to be lower in HBCS cows than in NBCS cows (Figure 4).

The muscle metabolites that were affected by time (regardless of treatment) during the transition from late gestation to early lactation in dairy cows are presented in Table 1. Muscle acylcarnitines including acetylcarnitine (C2), hexanoylcarnitine (fumarylcarnitine) [C6 (C4:1-DC)], pimelylcarnitine, hydroxyhexadecadienylcarnitine (C16:2-OH), octadecanoylcarnitine (C18), and octadecadienylcarnitine (C18:2) changed over time $[P \leq 0.05$, except for C6 (C4:1-DC), $P=$ 0.08 ] and followed a similar pattern; that is, they had lowest concentrations on $\mathrm{d}-49$, followed by $\mathrm{d} 3$, and highest concentrations on $\mathrm{d} 21$ and 84. Three AA including $\alpha$-aminoadipic acid $(\boldsymbol{\alpha}$-AAAA), histidine, and citrulline changed over time $(P \leq 0.04)$ in muscle. Muscle $\alpha$-AAA increased from d -49 to 3 , declined to almost prepartum values by $\mathrm{d} 21$ and then remained unchanged. Muscle histidine and citrulline were elevated from $\mathrm{d}-49$ to 21 and then remained unchanged.

\section{DISCUSSION}

In the current study, we used a targeted metabolomics, in which a specific set of known compounds are identified and quantified. This approach is a hypothesis-testing application and is generally used to provide absolute quantification of well-defined groups of metabolites or metabolic pathways of interest. We tested the hypothesis that a targeted metabolomic analysis of skeletal muscle would reveal dynamic markers of key regulatory metabolic intermediates, primarily belonging to the muscle lipidome associated with calving BCS 
A
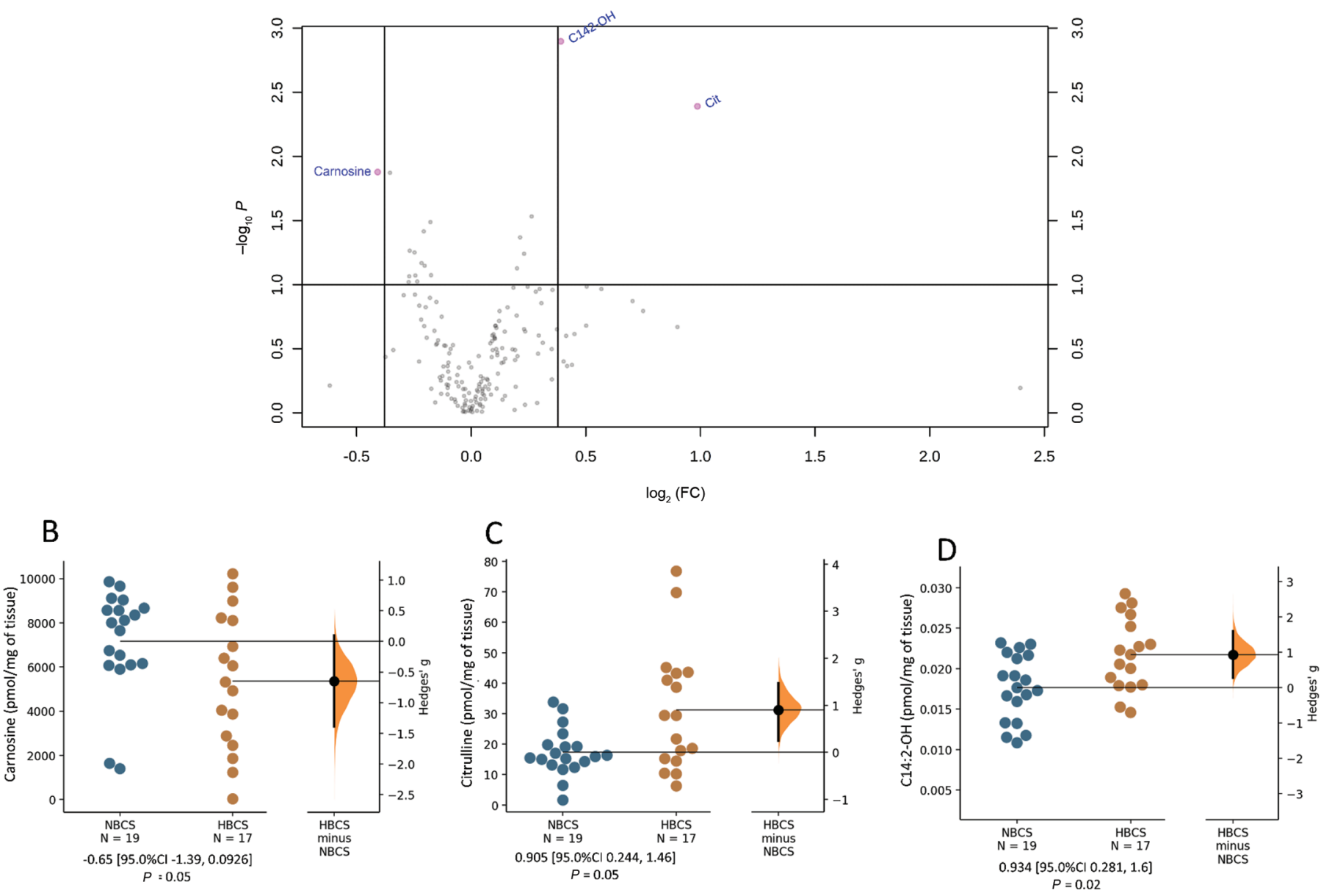

Figure 2. (A) Volcano plot visualizing muscle metabolites that differed between high-conditioned (HBCS) and normal-conditioned (NBCS) cows on $\mathrm{d}-49$ relative to calving. The $\mathrm{x}$-axis represents the mean of $\log _{2}$ fold-change (FC) value, and the $\mathrm{y}$-axis corresponds to the negative logarithm of the $P$-values. Each circle represents a single metabolite. The horizontal line represents the level of significance for the $t$ tests performed (0.10), and the vertical lines display the threshold set for fold change (1.3). The pink circles show metabolites that were significantly changed and the gray circles show metabolites that were not significantly changed. Effect size, shown as Hedges' $g$ between NBCS and HBCS cows, is shown in the Gardner-Altman estimation plots of muscle (B) carnosine, (C) citrulline (Cit), and (D) hydroxytetradecadienylcarnitine (C14:2 $-\mathrm{OH})$. Both groups are plotted on the left axes; the mean difference is plotted on floating axes on the right as a bootstrap sampling distribution. The mean difference is depicted as a dot; the $95 \%$ confidence interval is indicated by the ends of the vertical error bar.

and BCS loss postpartum. Another main approach for carrying out metabolic profiling - untargeted metabolomics - is a hypothesis-generating discovery application and allows for detection of a broad range of known and unknown metabolites.

Carnosine is an abundant endogenous dipeptide ( $\beta$-alanine and L-histidine) synthesized primarily in skeletal muscle, where it plays various important roles such as pH-buffering and metal-ion chelation; it also has antioxidant properties (Boldyrev et al., 2013). As reported previously (Ghaffari et al., 2019a), in contrast to muscle, serum concentrations of carnosine were higher in HBCS cows than in NBCS cows on $d-49$. Skeletal muscle, which contains the vast majority of the carnosine present in the body, is among the few tissues with very high expression of the enzyme responsible for carnosine synthesis (carnosine synthase; Boldyrev, 2012). This may point to a possible role for skeletal muscle as a production, storage, and release organ for carnosine (Boldyrev, 2012). Thus, as part of a physiological regulatory process, skeletal muscle that synthesizes carnosine can also release it into the circulation, probably through dipeptide transporters, to supply the needs of other tissues where it can be degraded or used (e.g., for delivery of L-histidine or $\beta$-alanine; Boldyrev, 2012). The finding that not only carnosine but also serum histidine concentrations were greater in HBCS cows on d -49 (Ghaffari et al., 2019b), may indicate 
that a proportion of the released carnosine might have been hydrolyzed. The physiological function of such a mechanism in dairy cows needs to be elucidated.

One of our findings was that levels of citrulline were higher in HBCS cows than in NBCS cows on $\mathrm{d}-49$. Citrulline, a nonessential and nonproteinogenic AA, was considered for a long time to be an intermediate of the urea cycle and just one of many AA (Breuillard et al., 2015). However, other metabolic properties of this AA have become known over time: it is a precursor of nitric oxide (Romero et al., 2006; Figueroa et al., 2017), and a modulator of nitrogen homeostasis (Breuillard et al., 2015), probably by acting as a regulator of muscle protein synthesis (Osowska et al., 2006). The reason for the greater concentrations of citrulline observed in HBCS cows on d -49 is not clear, but this finding might be explained, at least in part, by the different diets used in these cows from wk 15 to 7 before calving, because the observed differences disappeared on $\mathrm{d} 3$ (i.e., when the cows received identical diets). Citrulline can be synthesized from other AA, including glutamine, proline, and glutamate (Curis et al., 2005). However, we did not observe any differences in the concentrations of these metabolites in muscle on $\mathrm{d}-49$.

Among the measured acylcarnitines was 1 metabolite, $\mathrm{C} 14: 2-\mathrm{OH}$, that was elevated in the muscle of HBCS
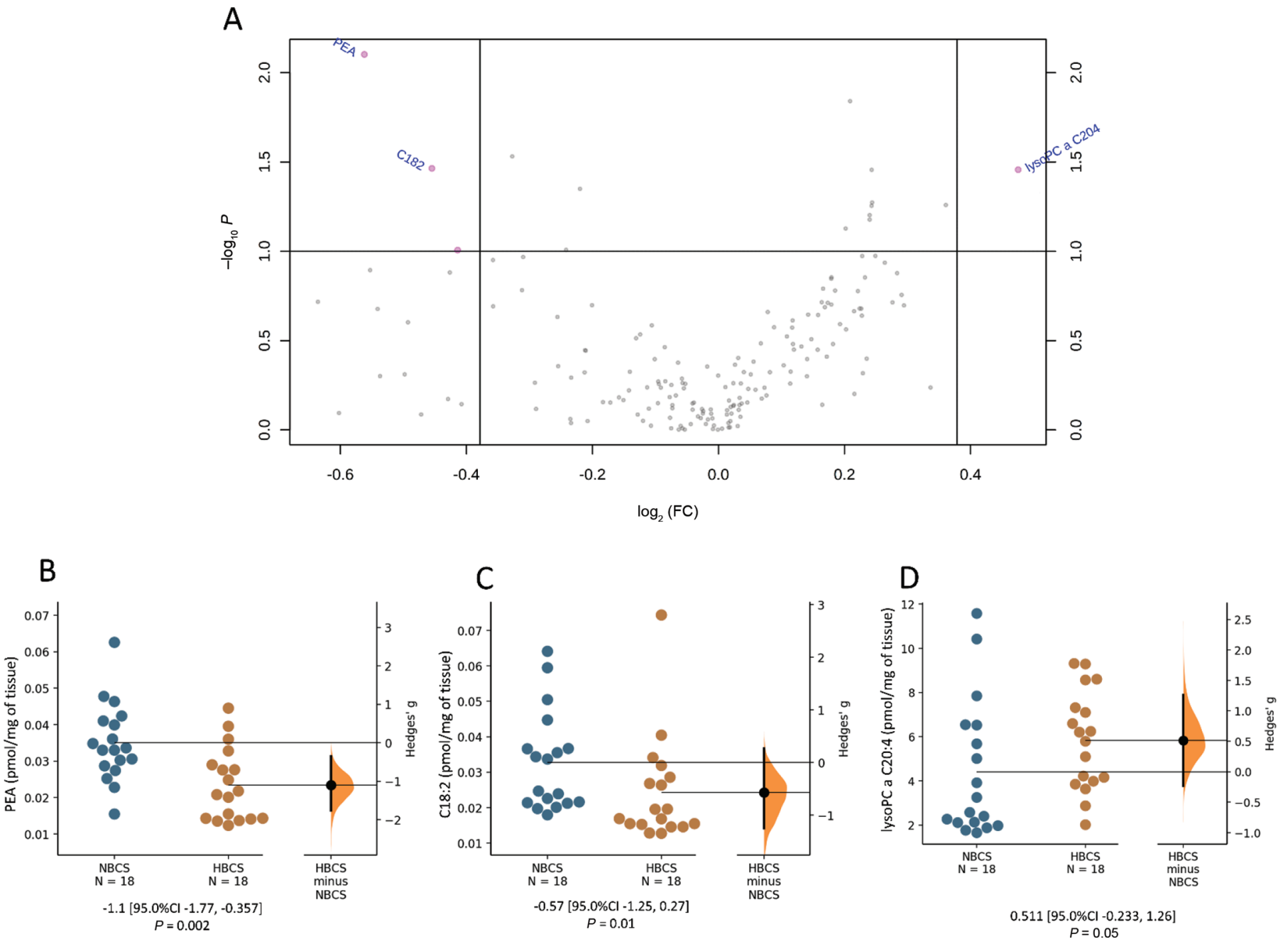

Figure 3. (A) Volcano plot visualizing muscle metabolites that differed between high-conditioned (HBCS) and normal-conditioned (NBCS) cows on $d+21$ relative to calving. The $\mathrm{x}$-axis represents the mean of $\log _{2}$ fold-change (FC) value, and the y-axis corresponds to the negative logarithm of the $P$-values. Each circle represents a single metabolite. The horizontal line represents the level of significance for the $t$ tests performed (0.10), and the vertical lines display the threshold set for fold change (1.3). The pink circles show metabolites that were significantly changed and the gray circles show metabolites that were not significantly changed. Effect size, shown as Hedges' $g$ between NBCS and HBCS cows, is shown in the Gardner-Altman estimation plots of muscle (B) phenylethylamine (PEA), (C) octadecadienylcarnitine (C18:2), and (D) lysophosphatidylcholine acyl C20:4 (lysoPC a C20:4). Both groups are plotted on the left axes; the mean difference is plotted on floating axes on the right as a bootstrap sampling distribution. The mean difference is depicted as a dot; the $95 \%$ confidence interval is indicated by the ends of the vertical error bar. 
cows on $\mathrm{d}-49$. The long-chain acylcarnitine $\mathrm{C} 14: 2-\mathrm{OH}$ is the carnitinated form of $\mathrm{C} 14: 2-\mathrm{OH}-\mathrm{CoA}$, an intermediate produced during $\beta$-oxidation of tetradecadienoic acid ( 1 cycle) or linoleic acid (2 cycles; Mirzoyan et al., 2017). In diabetic mice, $\mathrm{C} 14: 2-\mathrm{OH}$ was positively correlated with the ratio of urine albuminuria to urine creatinine, glomerular hypertrophy, blood glucose, and plasma lipids (Mirzoyan et al., 2017). This metabolite might also be an important marker of or contributor to underlying changes in the metabolism of skeletal muscle due to over-conditioning, and it warrants further investigation.

In the current study, the concentrations of lysoPC a C20:4 in muscle, were elevated in HBCS cows compared to NBCS cows on d 21. Lysophosphatidcholines have structural and signaling roles and originate primarily from cell-membrane-derived phosphatidylcholine (PC) hydrolysis catalyzed by phospholipase A2 (van der Veen et al., 2017). Different lysophospholipids are distinguished by their length and the saturation of their

A
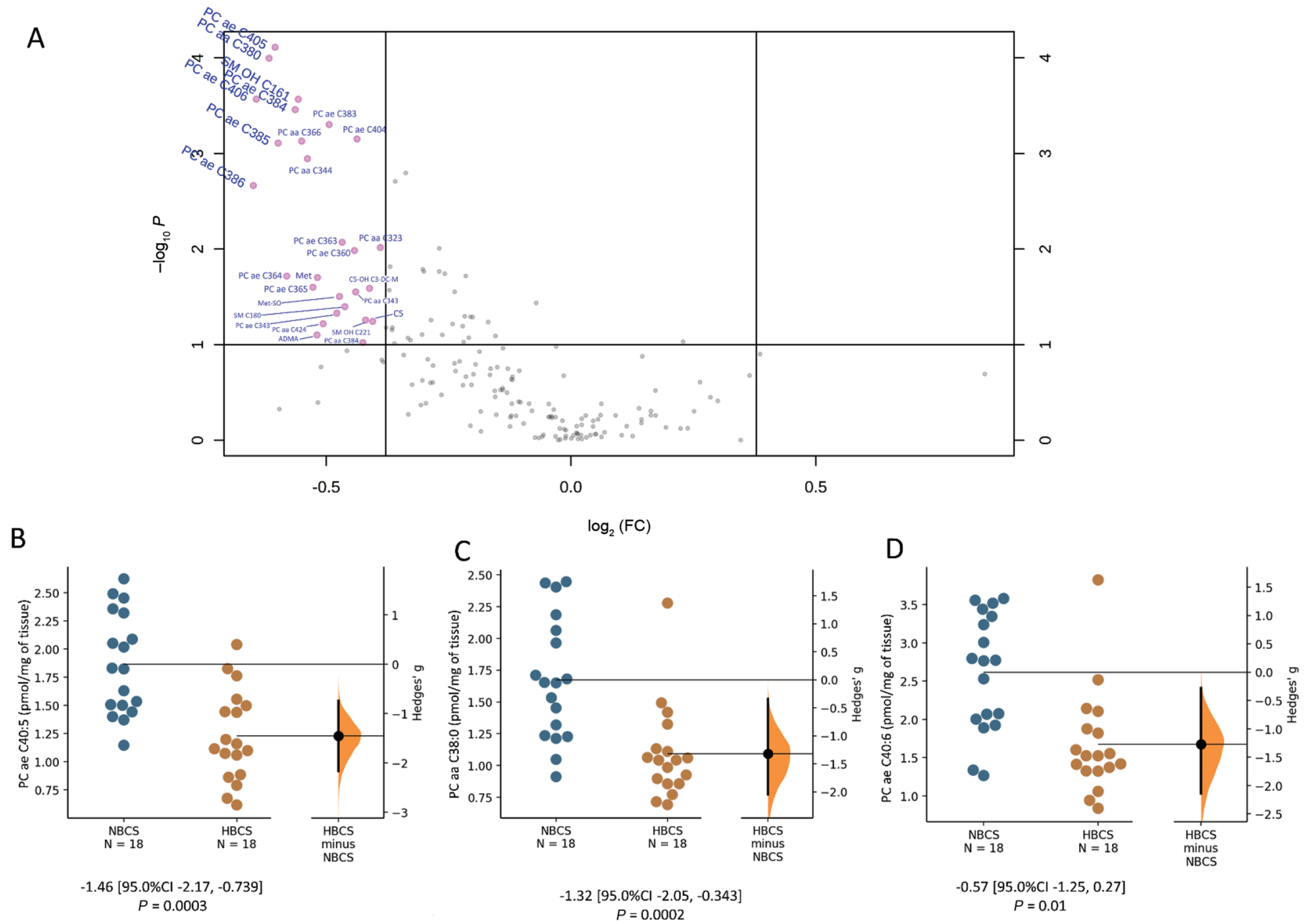

Figure 4. (A) Volcano plot visualizing muscle metabolites that differed between high-conditioned (HBCS) and normal-conditioned (NBCS) cows on $d+84$ relative to calving. The x-axis represents the mean of $\log _{2}$ fold-change (FC) value, and the y-axis corresponds to the negative logarithm of the $P$-values. Each circle represents a single metabolite. The horizontal line represents the level of significance for the $t$ tests performed (0.10), and the vertical lines display the threshold set for fold change (1.3). The pink circles show metabolites that were significantly changed and the gray circles show metabolites that were not significantly changed. Effect size, shown as Hedges' $g$ between NBCS and HBCS cows, is shown in the above Gardner-Altman estimation plots of muscle (B) acyl alkyl phosphatidylcholine (PC ae) C40:5, (C) di-acyl phosphatidylcholine (PC aa) C38:0, (D) PC ae C40:6, (E) PC ae C38:5, (F) PC ae C38:6, (G) hydroxysphingomyeline [(SM (OH)] C16:1, (H) PC ae C38:3, (I) PC ae C38:4, (J) PC ae C40:4, (K) PC aa C36:6, (L) PC aa C34:4, (M) PC ae C36:3, (N) PC aa C32:3, (O) PC aa C36:0, (P) PC ae C36:4, (Q) methionine (Met), (R) PC ae C36:5, (S) hydroxyvaleryl-/-isovaleryl-/-methylbutyryl-carnitine [C5-OH (C3-DC-M)], (T) PC aa C34:3, (U) methionine sulfoxide (Met-SO), (V) valeryl-carnitine (C5), (W) sphingomyelin (SM) C18:0, (X) PC ae C34:3, (Y) SM (OH) C22:1, (Z) PC aa C42:4, (ZZ) PC aa C38:4, and (ZY) asymmetric dimethyl-arginine (ADMA). Both groups are plotted on the left axes; the mean difference is plotted on floating axes on the right as a bootstrap sampling distribution. The mean difference is depicted as a dot; the $95 \%$ confidence interval is indicated by the ends of the vertical error bar. 
$\mathrm{E}$

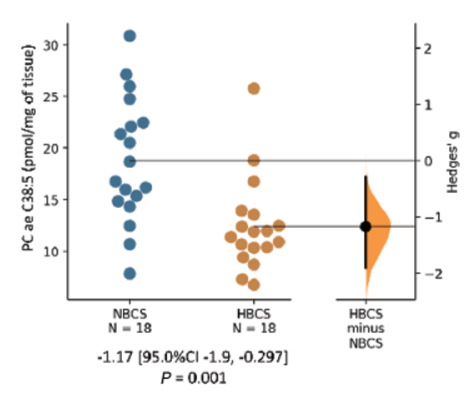

$\mathrm{H}$

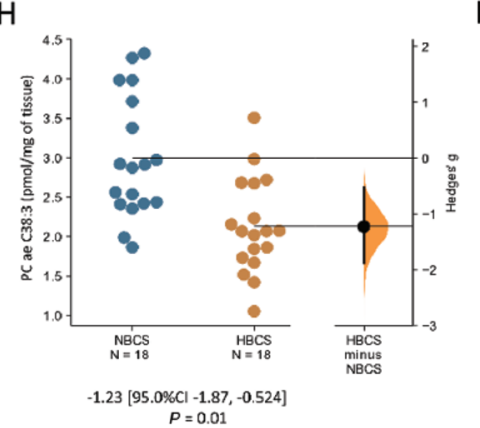

$\mathrm{F}$

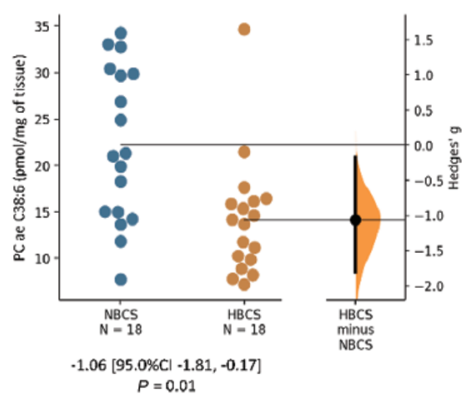

1

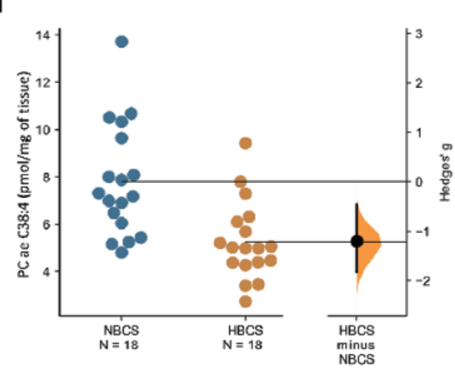

$-1.21[95.0 \% \mathrm{Cl}-1.82,-0.463]$
G

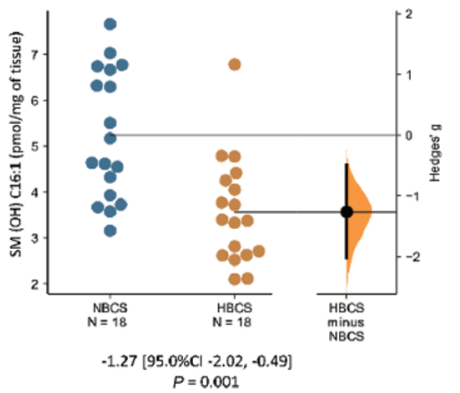

J

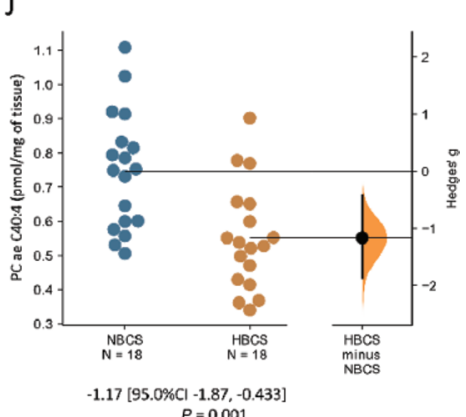

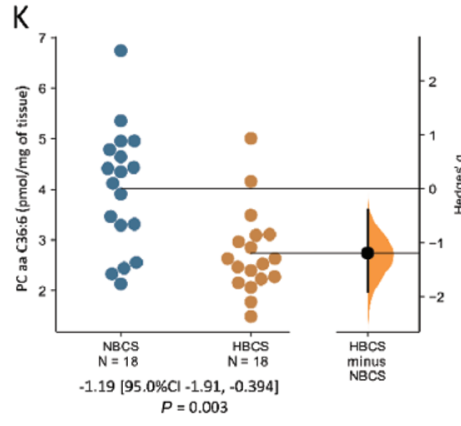
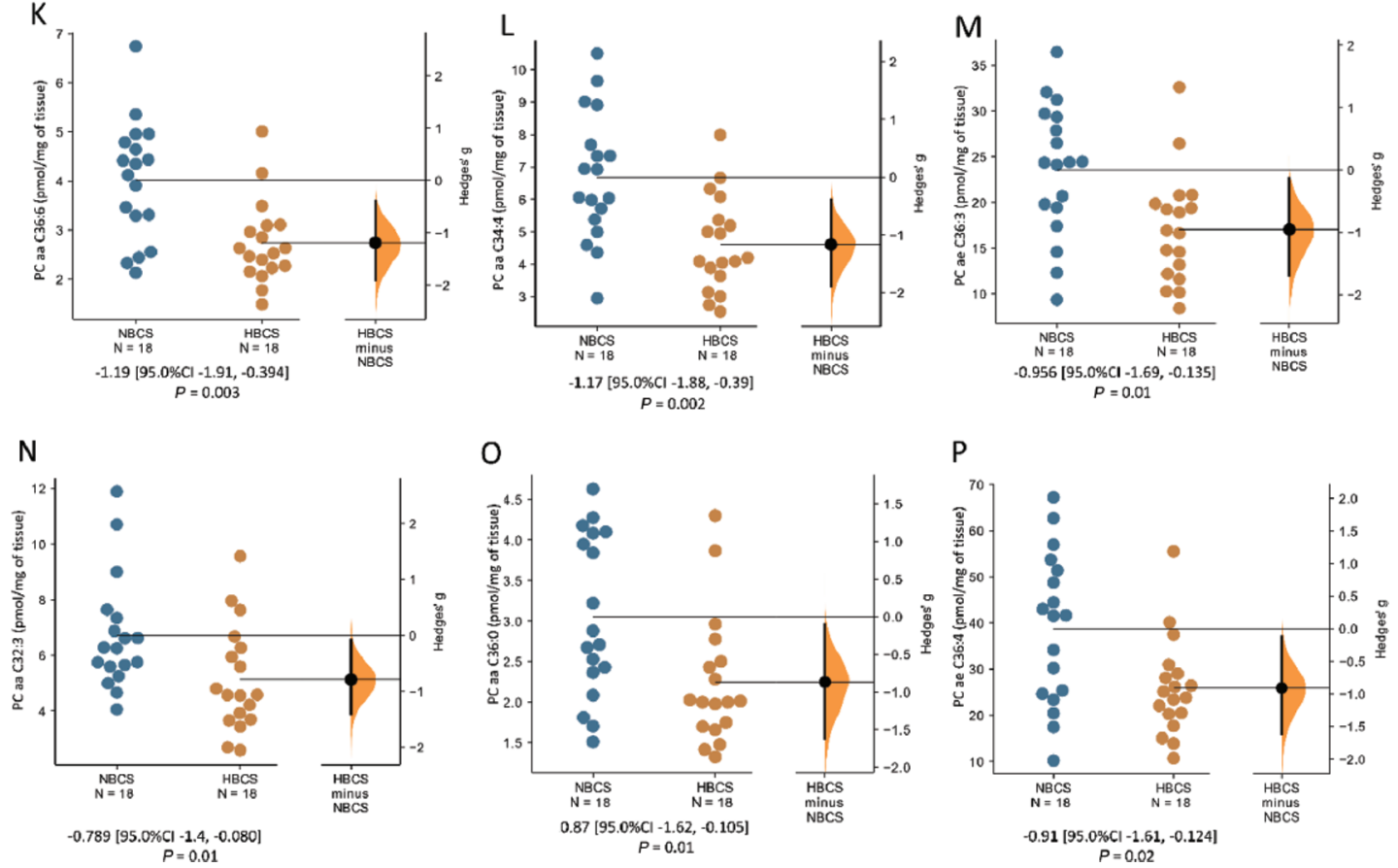

Figure 4 (Continued). (A) Volcano plot visualizing muscle metabolites that differed between high-conditioned (HBCS) and normal-conditioned (NBCS) cows on $\mathrm{d}+84$ relative to calving. The $\mathrm{x}$-axis represents the mean of $\log _{2}$ fold-change (FC) value, and the $\mathrm{y}$-axis corresponds to the negative logarithm of the $P$-values. Each circle represents a single metabolite. The horizontal line represents the level of significance for the $t$ tests performed $(0.10)$, and the vertical lines display the threshold set for fold change (1.3). The pink circles show metabolites that were significantly changed and the gray circles show metabolites that were not significantly changed. Effect size, shown as Hedges' $g$ between NBCS and HBCS cows, is shown in the above Gardner-Altman estimation plots of muscle (B) acyl alkyl phosphatidylcholine (PC ae) C40:5, (C) diacyl phosphatidylcholine (PC aa) C38:0, (D) PC ae C40:6, (E) PC ae C38:5, (F) PC ae C38:6, (G) hydroxysphingomyeline [(SM (OH)] C16:1, (H) PC ae C38:3, (I) PC ae C38:4, (J) PC ae C40:4, (K) PC aa C36:6, (L) PC aa C34:4, (M) PC ae C36:3, (N) PC aa C32:3, (O) PC aa C36:0, (P) PC ae C36:4, (Q) methionine (Met), (R) PC ae C36:5, (S) hydroxyvaleryl-/-isovaleryl-/-methylbutyryl-carnitine [C5-OH (C3-DC-M)], (T) $\mathrm{PC}$ aa C34:3, (U) methionine sulfoxide (Met-SO), (V) valeryl-carnitine (C5), (W) sphingomyelin (SM) C18:0, (X) PC ae C34:3, (Y) SM (OH) $\mathrm{C} 22: 1$, (Z) PC aa C42:4, (ZZ) PC aa C38:4, and (ZY) asymmetric dimethyl-arginine (ADMA). Both groups are plotted on the left axes; the mean difference is plotted on floating axes on the right as a bootstrap sampling distribution. The mean difference is depicted as a dot; the $95 \%$ confidence interval is indicated by the ends of the vertical error bar. 

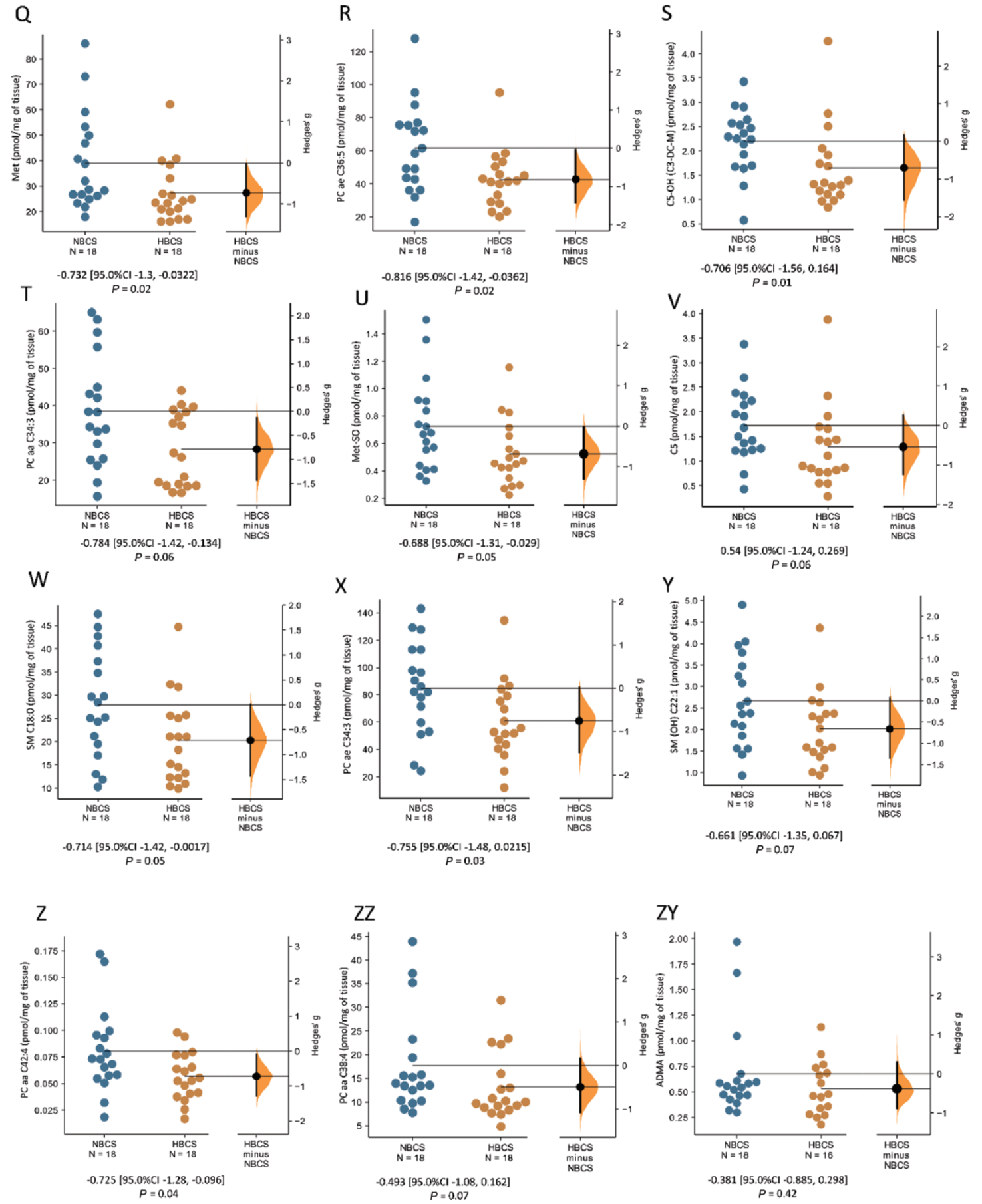

Figure 4 (Continued). (A) Volcano plot visualizing muscle metabolites that differed between high-conditioned (HBCS) and normal-conditioned (NBCS) cows on $\mathrm{d}+84$ relative to calving. The $\mathrm{x}$-axis represents the mean of $\log _{2}$ fold-change (FC) value, and the y-axis corresponds to the negative logarithm of the $P$-values. Each circle represents a single metabolite. The horizontal line represents the level of significance for the $t$ tests performed (0.10), and the vertical lines display the threshold set for fold change (1.3). The pink circles show metabolites that were significantly changed and the gray circles show metabolites that were not significantly changed. Effect size, shown as Hedges' $g$ between NBCS and HBCS cows, is shown in the above Gardner-Altman estimation plots of muscle (B) acyl alkyl phosphatidylcholine (PC ae) C40:5, (C) diacyl phosphatidylcholine (PC aa) C38:0, (D) PC ae C40:6, (E) PC ae C38:5, (F) PC ae C38:6, (G) hydroxysphingomyeline [(SM (OH)] C16:1, (H) PC ae C38:3, (I) PC ae C38:4, (J) PC ae C40:4, (K) PC aa C36:6, (L) PC aa C34:4, (M) PC ae C36:3, (N) PC aa C32:3, (O) PC aa C36:0, (P) PC ae C36:4, (Q) methionine (Met), (R) PC ae C36:5, (S) hydroxyvaleryl-/-isovaleryl-/-methylbutyryl-carnitine [C5-OH (C3-DC-M)], (T) PC aa C34:3, (U) methionine sulfoxide (Met-SO), (V) valeryl-carnitine (C5), (W) sphingomyelin (SM) C18:0, (X) PC ae C34:3, (Y) SM (OH) $\mathrm{C} 22: 1$, (Z) PC aa C42:4, (ZZ) PC aa C38:4, and (ZY) asymmetric dimethyl-arginine (ADMA). Both groups are plotted on the left axes; the mean difference is plotted on floating axes on the right as a bootstrap sampling distribution. The mean difference is depicted as a dot; the $95 \%$ confidence interval is indicated by the ends of the vertical error bar. 
acyl chains (van der Veen et al., 2017). Lysophospholipids, mainly lysoPC, seem to be important molecules in obesity and related disorders (Pietiläinen et al., 2007; Barber et al., 2012; Heimerl et al., 2014). Obesity has been shown to have a substantial effect on lysophospholipid metabolism, leading to changes in the plasma lysophospholipid profile and apparently contributing to the onset or progression of alterations associated with obesity, such as inflammation, insulin resistance, and fatty liver disease (del Bas et al., 2016) through their interaction with $\mathrm{G}$ protein-coupled receptors (Grzelczyk and Gendaszewska-Darmach, 2013). Han et al. (2011) have reported that lysoPC levels were increased in the muscle of insulin-resistant $\mathrm{db} / \mathrm{db}$ mice and provided evidence showing that lysoPC were acting as mediators of FA-induced insulin resistance in L6 myotubes. Increased concentrations of lysoPC species may suggest that the onset of the alterations related to obesity are associated with transient increases of lysoPC (del Bas et al., 2016). Whether lysoPC acts in the same manner in dairy cows is unknown, and clarification is needed of the predictive capacity and role of specific lysoPC species including lysoPC a C20:4 in metabolic status associated with over-conditioning. However, the changes observed in muscle PC profiles from d 21 to 84 in HBCS cows support a sequential time course of increased lysoPC a C20:4, followed by a reduction of $\mathrm{PC}$. Because of our study design, we were unable to assess whether changes in lysoPC a C20:4 between d 21 and 84 were transient or long-lasting changes.

In the current study, muscle concentrations of PEA were lower in HBCS cows than in NBCS cows on d 21.
Phenylethylamine is an endogenous neurotransmitter, likely acting as a neuromodulator for catecholamines. This metabolite is synthesized from the AA phenylalanine by the action of aromatic AA decarboxylase (Irsfeld et al., 2013). Phenylethylamine is known for its antidepressant effects, and the biochemical effects of this metabolite in human and laboratory animal have been studied with an emphasis on the possible relevance of its antidepressant action. The presence of this metabolite has been reported in bovine mammary epithelial cells (Fusi et al., 2008) as well as in cow biofluids (rumen fluid, serum, milk, and urine; Sun et al., 2017) and liver (Suzuki et al., 1980); however, to our knowledge no data are available describing PEA content in other tissues of ruminants, including skeletal muscle. These limited data make it difficult to draw conclusions about the potential roles of PEA in the skeletal muscle of periparturient dairy cows.

In the current study, the decrease in long-chain acylcarnitine $\mathrm{C} 18: 2$ in the muscle of HBCS cows on $\mathrm{d}$ 21 coincided with greater negative energy balance and more intense mobilization of body fat, as evidenced by greater BCS and BFT loss, as well as elevated concentrations of nonesterified fatty acids and BHB in the serum of HBCS cows (Schuh et al., 2019). Increased concentrations of medium- and long-chain acylcarnitines reflect the excess of lipolysis-derived nonesterified fatty acids, resulting in mitochondrial overload and release of acylcarnitines as intermediates of $\beta$-oxidation (Wolf et al., 2013). At present, we have no explanation for the observed decrease in the muscle concentrations of C18:2 in HBCS cows on d 21. However, we could

Table 1. The muscle metabolites (pmol/mg of tissue; least squares means $\pm \mathrm{SEM}$ ) that were affected by time $(P<0.05)$ during the transition from late gestation to early lactation in dairy cows

\begin{tabular}{|c|c|c|c|c|c|c|}
\hline \multirow[b]{2}{*}{ Item $^{1}$} & \multicolumn{4}{|c|}{ Days relative to calving } & \multirow[b]{2}{*}{ SEM } & \multirow[b]{2}{*}{$P$-value } \\
\hline & -49 & +3 & +21 & +84 & & \\
\hline \multicolumn{7}{|l|}{ Acylcarnitine } \\
\hline $\mathrm{C} 2$ & $234^{\mathrm{b}}$ & $256^{\mathrm{b}}$ & $329^{\mathrm{a}}$ & $304^{\mathrm{ab}}$ & 26.7 & 0.03 \\
\hline C6 (C4:1-DC) & $0.316^{\mathrm{b}}$ & $0.370^{\mathrm{ab}}$ & $0.365^{\mathrm{ab}}$ & $0.402^{\mathrm{a}}$ & 0.01 & 0.08 \\
\hline $\mathrm{C} 7-\mathrm{DC}$ & $0.081^{\mathrm{b}}$ & $0.090^{\mathrm{ab}}$ & $0.096^{\mathrm{a}}$ & $0.091^{\mathrm{ab}}$ & 0.01 & 0.05 \\
\hline $\mathrm{C} 16: 2-\mathrm{OH}$ & $0.050^{\mathrm{b}}$ & $0.050^{\mathrm{b}}$ & $0.053^{\mathrm{a}}$ & $0.054^{\mathrm{a}}$ & 0.001 & 0.02 \\
\hline $\mathrm{C} 18$ & $0.186^{\mathrm{b}}$ & $0.212^{\mathrm{ab}}$ & $0.255^{\mathrm{a}}$ & $0.289^{\mathrm{a}}$ & 0.02 & 0.05 \\
\hline $\mathrm{C} 18: 2$ & $0.024^{\mathrm{b}}$ & $0.022^{\mathrm{b}}$ & $0.028^{\mathrm{a}}$ & $0.031^{\mathrm{a}}$ & 0.002 & 0.02 \\
\hline \multicolumn{7}{|l|}{ Amino acid } \\
\hline$\alpha-\mathrm{AAA}$ & $10.9^{\mathrm{b}}$ & $15.2^{\mathrm{a}}$ & $11.1^{\mathrm{b}}$ & $13.2^{\mathrm{ab}}$ & 1.87 & 0.01 \\
\hline Histidine & $79.8^{\mathrm{b}}$ & $99.1^{\mathrm{ab}}$ & $107^{\mathrm{a}}$ & $104^{\mathrm{ab}}$ & 4.08 & 0.03 \\
\hline Citrulline & $23.9^{\mathrm{b}}$ & $26.0^{\mathrm{b}}$ & $31.2^{\mathrm{a}}$ & $31.7^{\mathrm{a}}$ & 2.86 & 0.04 \\
\hline
\end{tabular}

${ }^{\mathrm{a}, \mathrm{b}}$ Values within a row with different letters differ by post hoc testing (Tukey's honestly significant difference) after repeated-measures ANOVA.

${ }^{1} \alpha$-AAA $=\alpha$-aminoadipic acid; C2 = acetylcarnitine; C6 (C4:1-DC) = hexanoylcarnitine (fumarylcarnitine); $\mathrm{C} 7-\mathrm{DC}=$ pimelylcarnitine; $\mathrm{C} 16: 2-\mathrm{OH}=$ hydroxyhexadecadienylcarnitine; C18 = octadecanoylcarnitine; C18:2 $=$ octadecadienylcarnitine. 
speculate that an increased oxidative capacity for FA in skeletal muscle might have contributed to reducing the metabolic load of FA in the liver of HBCS cows.

The plasma membranes of many mammalian cells contain several distinct phospholipid species with considerable variation in their FA composition that may alter the structure and dynamics of the membrane and affect the function of membrane-bound proteins and their actions (van der Veen et al., 2017). Phosphatidylcholine and phosphatidylethanolamine are the most abundant membrane phospholipid constituents, with phosphatidylcholine accounting for approximately $50 \%$ of the total phospholipid species and phosphatidylethanolamine accounting for another 20 to 30\% (Takagi, 1971). In addition, SM, which make up about 10 to $15 \%$ of lipids in the plasma membrane, are a molecularly diverse group of phospholipids. They are composed of a backbone of ceramide base and a phosphocholine head group (Gault et al., 2010; Slotte, 2013). Thus, PC and SM play critical roles in regulating membrane structure and integrity, protein dynamics, and cellular signaling (Gault et al., 2010; Slotte, 2013; van der Veen et al., 2017). In the current study, the significantly changed metabolites on d 84 were mainly long-chain (>C32) PC ae and $\mathrm{PC}$ aa, along with 3 long-chain SM that were all lower in HBCS cows than in NBCS cows. It has been well documented that the phospholipid acyl composition of skeletal muscle is related to insulin sensitivity in humans (Borkman et al., 1993; Vessby et al., 1994; Pan et al., 1995). High levels of long-chain PUFA in skeletal muscle membrane phospholipids were positively associated with estimates (e.g., fasting plasma insulin) and direct measures (e.g., hyperinsulinemic-euglycemic clamp) of insulin sensitivity (Borkman et al., 1993; Vessby et al., 1994; Pan et al., 1995). Greater insulin sensitivity in cells with membranes that have increased PUFA content is likely due to increased membrane fluidity and glucose uptake (GLUT-4 translocation) after insulin stimulation (Pilch et al., 1980), as well as enhanced insulin receptor kinetics (Pilch et al., 1980; Ginsberg et al., 1981; Nadiv et al., 1994). In the current study, muscle PC ae seemed to be more influenced by degree of saturation than by chain length. This might indicate a shift from PUFA toward saturated or monosaturated FA PC in the muscle cell membrane of HBCS cows. We therefore speculate that these changes might result in an increase of membrane stiffness, which may be associated with abnormalities in insulin signaling and glucose transporter translocation in the muscle of HBCS cows. As reported previously from this experiment, HBCS cows had greater insulin concentrations than NBCS cows across all time points, but differences could not be assigned to individual time points (Schuh et al., 2019). In addition, greater insulin concentra- tions coincided with greater glucose concentrations in HBCS cows, likely pointing to decreased insulin sensitivity (Schuh et al., 2019). The notion that high BCS is associated with decreased insulin sensitivity is quite common, but is mainly based on surrogate indices for insulin sensitivity and not on clamp studies considered the gold standard for assessing insulin sensitivity. However, clamp studies performed in dry or late lactating cows are in support of an association between decreased insulin sensitivity and increased BCS (e.g., De Koster et al., 2015). Insulin sensitivity was reported to be, in part, dependent on muscle fiber type (Clore et al., 1998). In the current study, the muscle biopsy was obtained only from the semitendinosus muscle, and muscle fiber type composition was not determined in the samples; it is likely that each fiber type contributes differently in response to over-conditioning. The response of muscles with different fiber types to over-conditioning in dairy cows has yet to be determined.

In addition to its role as the building block of proteins, Met is essential for many important cellular and biosynthetic functions, including the initiation of protein synthesis. Methionine sulfoxide, the oxidized form of Met, originates from oxidation of the sulfur of Met, which takes place under both physiological and pathophysiological conditions (Vogt, 1995). Compared with the other AA, the sulfur-containing AA (i.e., Met and cysteine) are more readily oxidized. Nevertheless, in contrast to other AA, Met-SO can be reduced by $\mathrm{NAD}(\mathrm{P}) \mathrm{H}$ dependent enzymatic action, through MetSO reductases (Levine et al., 2000). Therefore, Met-SO has been suggested as a potential biomarker for oxidative stress, in particular for oxidative protein damage (Levine et al., 2000). The reasons for lower Met in the muscle of HBCS cows on d 84 that might reflect lower protein synthesis in the muscle of HBCS cows are not clear. However, lower muscle Met-SO is likely due to less available free Met that could be oxidized to MetSO.

Skeletal muscle plays important roles in coping with the increasing concentrations of FA during late gestation and early lactation. In the current study, the longitudinal changes in muscle metabolites during the transition from pregnancy into lactation showed that muscle $\mathrm{C} 2$ concentrations on $\mathrm{d} 21$ were greater than those on d -49 and 3, which were accompanied by the elevated concentrations of muscle long-chain acylcarnitine species $\mathrm{C} 16: 2-\mathrm{OH}, \mathrm{C} 18$, and C18:2. Acetylcarnitine, the universal degradation product of all metabolic substrates, derives from acetyl-CoA by the action of carnitine acetyltransferase for transport out of the mitochondria (Flanagan et al., 2010). These results point to increased FA $\beta$-oxidation postpartum, which did not coincide with an upregulation of downstream 
metabolic pathways such as the tricarboxylic acid cycle and respiratory chain.

An interesting finding of the current study was the increased $\alpha$-AAA in the muscle of dairy cows on $\mathrm{d}$ 3 compared with d -49 and 21. aAminoadipic acid, a non-proteinogenic $\alpha-\mathrm{AA}$, is an intermediate in the metabolism of lysine. Studies in rats have shown that plasma $\alpha$-AAA concentrations, along with those of 3 branched-chain AA (leucine, isoleucine, and valine), are elevated in the prediabetic phase, and $\alpha$-AAA may thus serve as a predictive biomarker for the development of diabetes (Wijekoon et al., 2004). In support of this, Wang et al. (2013) found that $\alpha$-AAA is a marker of diabetes risk and a potential modulator of glucose homeostasis in humans. In addition, $\alpha$-AAA has been identified as a potential small-molecule marker of oxidative stress (Zeitoun-Ghandour et al., 2011). Whether $\alpha$-AAA acts in the same manner in dairy cows is currently unknown; however, on the basis of these previous studies and on our observations, muscle $\alpha$-AAA might contribute to a reduction of insulin sensitivity in the skeletal muscle of dairy cows immediately postpartum.

In the current study, concentrations of proteinogenic AA (except for histidine) in muscle remained fairly constant throughout the observation period despite, as reported previously (Ghaffari et al., 2019b), a concomitant decline in serum levels. The reason for these observations is not clear, but it is likely that muscle has increased transport activity to offset the decline in serum concentrations and thus maintain intracellular concentrations of the respective AA, assuming measurement at a single time point is reflective of the steady state.

As stated above, besides other metabolic properties, citrrulline has been shown as a modulator of nitrogen homeostasis (Breuillard et al., 2015), likely by acting as a regulator of muscle protein synthesis (Osowska et al., 2006). Thus, the elevated concentration of muscle citrulline observed on d 21 and 84 in the current study might imply contribution of this AA in the move of skeletal muscle toward anabolism, and warrants further investigation.

\section{CONCLUSIONS}

Overall, our results suggest that over-conditioning has an effect on PC metabolism, modifying the profile of muscle lysoPC and long-chain PC. Because of the role of lysoPC and $\mathrm{PC}$ as signaling molecules that modulate processes that are usually altered in obesity, these data may provide more evidence for understanding the mechanisms that favor the progression of alterations such as insulin sensitivity and inflammation in the muscle of HBCS cows. Considering the literature, small alterations in phospholipid levels appear to have broad implications for several functions in skeletal muscle linked to mitochondria, cell growth, inflammation, and insulin sensitivity. More research is needed to better understand how alterations in phospholipid composition in muscle may contribute to regulating the activity of membrane proteins involved in insulin signaling and energy metabolism in over-conditioned cows. Moreover, the role of other significantly changed metabolites, including citrulline, hydroxytetradecadienyl-L-carnitine, carnosine, and phenylethylamine in metabolism, signaling, or immunological responses associated with overconditioning in dairy cows are not yet clear and need to be elucidated.

\section{ACKNOWLEDGMENTS}

The animal experiment underlying this research was conducted by the Educational and Research Centre for Animal Husbandry, Hofgut Neumuehle. We appreciate the help of Dörte Frieten (Educational and Research Centre for Animal Husbandry, Hofgut Neumuehle) during sampling of the cows. The scholarship for K. Schuh from the H. Wilhelm Schaumann Foundation (Hamburg, Germany) is gratefully acknowledged. The authors have not stated any conflicts of interest.

\section{REFERENCES}

Barber, M. N., S. Risis, C. Yang, P. J. Meikle, M. Staples, M. Febbraio, and C. R. Bruce. 2012. Plasma lysophosphatidylcholine levels are reduced in obesity and type 2 diabetes. PLoS One 7:e41456. https://doi.org/10.1371/journal.pone.0041456.

Bell, A. W., W. S. Burhans, and T. R. Overton. 2000. Protein nutrition in late pregnancy, maternal protein reserves and lactation performance in dairy cows. Proc. Nutr. Soc. 59:119-126. https:// doi.org/10.1017/S0029665100000148.

Berry, D. P., F. Buckley, and P. Dillon. 2007. Body condition score and live-weight effects on milk production in Irish Holstein-Friesian dairy cows. Animal 1:1351-1359. https://doi.org/10.1017/ S1751731107000419.

Boldyrev, A. A. 2012. Carnosine: New concept for the function of an old molecule. Biochemistry 77:313-326.

Boldyrev, A. A., G. Aldini, and W. Derave. 2013. Physiology and pathophysiology of carnosine. Physiol. Rev. 93:1803-1845. https:/ /doi.org/10.1152/physrev.00039.2012.

Borkman, M., L. H. Storlien, D. A. Pan, A. B. Jenkins, D. J. Chisholm, and L. V. Campbell. 1993. The relation between insulin sensitivity and the fatty-acid composition of skeletal-muscle phospholipids. N. Engl. J. Med. 328:238-244. https://doi.org/10.1056/ NEJM199301283280404.

Breuillard, C., L. Cynober, and C. Moinard. 2015. Citrulline and nitrogen homeostasis: An overview. Amino Acids 47:685-691. https: //doi.org/10.1007/s00726-015-1932-2.

Buckley, F., K. O'Sullivan, J. F. Mee, R. D. Evans, and P. Dillon. 2003. Relationships among milk yield, body condition, cow weight, and reproduction in spring-calved Holstein-Friesians. J. Dairy Sci. 86:2308-2319. https://doi.org/10.3168/jds.S0022-0302(03)73823 -5 .

Chibisa, G. E., G. N. Gozho, A. G. Van Kessel, A. A. Olkowski, and T. Mutsvangwa. 2008. Effects of peripartum propylene glycol supplementation on nitrogen metabolism, body composition, and gene 
expression for the major protein degradation pathways in skeletal muscle in dairy cows. J. Dairy Sci. 91:3512-3527. https://doi.org/ 10.3168/jds.2007-0920.

Chong, J., O. Soufan, C. Li, I. Caraus, S. Z. Li, G. Bourque, D. S. Wishart, and J. G. Xia. 2018. MetaboAnalyst 4.0: Towards more transparent and integrative metabolomics analysis. Nucleic Acids Res. 46(W1):W486-W494. https://doi.org/10.1093/nar/gky310.

Claridge-Chang, A., and P. N. Assam. 2016. Estimation statistics should replace significance testing. Nat. Methods 13:108-109. https://doi.org/10.1038/nmeth.3729.

Clore, J. N., J. Li, R. Gill, S. Gupta, R. Spencer, A. Azzam, W. Zuelzer, W. B. Rizzo, and W. G. Blackard. 1998. Skeletal muscle phosphatidylcholine fatty acids and insulin sensitivity in normal humans. Am. J. Physiol. 275:E665-E670. https://doi.org/10.1152/ ajpendo.1998.275.4.E665.

Crichton, N. 2000. Information point: Mann-Whitney test. J. Clin. Nurs. 9:583.

Curis, E., I. Nicolis, C. Moinard, S. Osowska, N. Zerrouk, S. Bénazeth, and L. Cynober. 2005. Almost all about citrulline in mammals. Amino Acids 29:177-205. https://doi.org/10.1007/s00726-005 -0235-4.

De Koster, J., M. Hostens, M. Van Eetvelde, K. Hermans, S. Moerman, H. Bogaert, E. Depreester, W. Van den Broeck, and G. Opsomer. 2015. Insulin response of the glucose and fatty acid metabolism in dry dairy cows across a range of body condition scores. J. Dairy Sci. 98:4580-4592. https://doi.org/10.3168/jds.2015-9341.

del Bas, J. M., A. Caimari, M. I. Rodriguez-Naranjo, C. E. Childs, C. Paras Chavez, A. L. West, E. A. Miles, L. Arola, and P. C. Calder. 2016. Impairment of lysophospholipid metabolism in obesity: Altered plasma profile and desensitization to the modulatory properties of n-3 polyunsaturated fatty acids in a randomized controlled trial. Am. J. Clin. Nutr. 104:266-279. https://doi.org/10.3945/ ajcn.116.130872.

Dervishi, E., G. Zhang, D. Hailemariam, R. Mandal, D. S. Wishart, and B. N. Ametaj. 2018. Urine metabolic fingerprinting can be used to predict the risk of metritis and highlight the pathobiology of the disease in dairy cows. Metabolomics 14:83. https://doi.org/ 10.1007/s11306-018-1379-z.

Drackley, J. K. 1999. Biology of dairy cows during the transition period: The final frontier? J. Dairy Sci. 82:2259-2273. https://doi .org/10.3168/jds.S0022-0302(99)75474-3.

Edmonson, A. J., I. J. Lean, L. D. Weaver, T. Farver, and G. Webster. 1989. A body condition scoring chart for Holstein dairy cows. J. Dairy Sci. 72:68-78.

Figueroa, A., A. Wong, S. J. Jaime, and J. U. Gonzales. 2017. Influence of L-citrulline and watermelon supplementation on vascular function and exercise performance. Curr. Opin. Clin. Nutr. Metab. Care 20:92-98. https://doi.org/10.1097/MCO.0000000000000340.

Flanagan, J. L., P. A. Simmons, J. Vehige, M. D. Willcox, and Q. Garrett. 2010. Role of carnitine in disease. Nutr. Metab. (Lond.) 7:30.

Fusi, E., A. Baldi, F. Cheli, R. Rebucci, E. Ayuso, K. Sejrsen, and S. Purup. 2008. Effects of putrescine, cadaverine, spermine, spermidine and $\beta$-phenylethylamine on cultured bovine mammary epithelial cells. Ital. J. Anim. Sci. 7:131-140. https://doi.org/10.4081/ ijas.2008.131.

Garnsworthy, P. C., and G. P. Jones. 1987. The influence of body condition at calving and dietary-protein supply on voluntary food intake and performance in dairy cows. Anim. Prod. 44:347-353. https://doi.org/10.1017/S0003356100012277.

Gärtner, T., E. Gernand, J. Gottschalk, and K. Donat. 2019. Relationships between body condition, body condition loss, and serum metabolites during the transition period in primiparous and multiparous cows. J. Dairy Sci. 102:9187-9199. https://doi.org/10 .3168/jds.2018-15762.

Gault, C. R., L. M. Obeid, and Y. A. Hannun. 2010. An overview of sphingolipid metabolism: From synthesis to breakdown. Adv. Exp. Med. Biol. 688:1-23. https://doi.org/10.1007/978-1-4419-6741-1 -1 .

GfE (Society of Nutrition Physiology). 2001 Ausschuss für Bedarfsnormen der Gesellschaft für Ernährungsphysiologie. Nr. 8. Empfehlungen zur Energie- und Nährstoffversorgung der Milchkühe und Aufzuchtrinder (Recommendations of Energy and Nutrient Supply for Dairy Cows and Breeding Cattle). DLG-Verlag, Frankfurt am Main, Germany.

Ghaffari, M. H., H. Sadri, K. Schuh, G. Dusel, D. Frieten, C. Koch, C. Prehn, J. Adamski, and H. Sauerwein. 2019a. Biogenic amines: Concentrations in serum and skeletal muscle from late pregnancy until early lactation in dairy cows with high versus normal body condition score. J. Dairy Sci. 102:6571-6586. https://doi.org/10 .3168/jds.2018-16034.

Ghaffari, M. H., K. Schuh, G. Dusel, D. Frieten, C. Koch, C. Prehn, J. Adamski. H. Sauerwein, and H. Sadri. 2019b. Mammalian target of rapamycin signaling and ubiquitin-proteasome-related gene expression in skeletal muscle of dairy cows with high or normal body condition score around calving. J. Dairy Sci. 102:11544-11560. https://doi.org/10.3168/jds.2019-17130.

Gillund, P., O. Reksen, Y. T. Grohn, and K. Karlberg. 2001. Body condition related to ketosis and reproductive performance in Norwegian dairy cows. J. Dairy Sci. 84:1390-1396. https://doi.org/10 .3168/jds.S0022-0302(01)70170-1.

Ginsberg, B. H., T. J. Brown, I. Simon, and A. A. Spector. 1981. Effect of the membrane lipid environment on the properties of insulin receptors. Diabetes 30:773-780. https://doi.org/10.2337/ diab.30.9.773.

Greenland, S., S. J. Senn, K. J. Rothman, J. B. Carlin, C. Poole, S. N. Goodman, and D. G. Altman. 2016. Statistical tests, P values, confidence intervals, and power: A guide to misinterpretations. Eur. J. Epidemiol. 31:337-350. https://doi.org/10.1007/s10654 $-016-0149-3$

Grzelczyk, A., and E. Gendaszewska-Darmach. 2013. Novel bioactive glycerol based lysophospholipids: New data-new insight into their function. Biochimie 95:667-679. https://doi.org/10.1016/j.biochi 2012.10.009.

Hailemariam, D., R. Mandal, F. Saleem, S. M. Dunn, D. S. Wishart, and B. N. Ametaj. 2014. Identification of predictive biomarkers of disease state in transition dairy cows. J. Dairy Sci. 97:2680-2693. https://doi.org/10.3168/jds.2013-6803.

Han, M. S., Y. M. Lim, W. Quan, J. R. Kim, K. W. Chung, M. Kang, S. Kim, S. Y. Park, J. S. Han, S. Y. Park, H. G. Cheon, S. Dal Rhee, T. S. Park, and M. S. Lee. 2011. Lysophosphatidylcholine as an effector of fatty acid-induced insulin resistance. J. Lipid Res. 52:1234-1246. https://doi.org/10.1194/jlr.M014787.

Hayirli, A., R. R. Grummer, E. V. Nordheim, and P. M. Crump. 2002. Animal and dietary factors affecting feed intake during the prefresh transition period in Holsteins. J. Dairy Sci. 85:3430-3443. https://doi.org/10.3168/jds.S0022-0302(02)74431-7.

Heimerl, S., M. Fischer, A. Baessler, G. Liebisch, A. Sigruener, S. Wallner, and G. Schmitz. 2014. Alterations of plasma lysophosphatidylcholine species in obesity and weight loss. PLoS One 9:e111348. https://doi.org/10.1371/journal.pone.0111348.

Ingvartsen, K. L., and J. B. Andersen. 2000. Integration of metabolism and intake regulation: A review focusing on periparturient animals. J. Dairy Sci. 83:1573-1597. https://doi.org/10.3168/jds .S0022-0302(00)75029-6.

Irsfeld, M., M. Spadafore, and B. M. Prüß. 2013. 3-phenylethylamine, a small molecule with a large impact. Webmedcentral 4:4409-4424.

Kuhla, B., G. Nürnberg, D. Albrecht, S. Görs, H. M. Hammon, and C. C. Metges. 2011. Involvement of skeletal muscle protein, glycogen, and fat metabolism in the adaptation on early lactation of dairy cows. J. Proteome Res. 10:4252-4262. https://doi.org/10.1021/ pr200425h.

Levine, R. L., J. Moskovitz, and E. R. Stadtman. 2000. Oxidation of methionine in proteins: Roles in antioxidant defense and cellular regulation. IUBMB Life 50:301-307. https://doi.org/10.1080/ 15216540051081056.

Meijer, G. A., J. Van der Meulen, J. G. Bakker, C. J. Van der Koelen, and A. M. Van Vuuren. 1995. Free amino acids in plasma and muscle of high yielding dairy cows in early lactation. J. Dairy Sci. 78:1131-1141. https://doi.org/10.3168/jds.S0022-0302(95)76730 $-3$.

Mirzoyan, K., K. Klavins, T. Koal, M. Gillet, D. Marsal, C. Denis, J. Klein, J. L. Bascands, J. P. Schanstra, and J. S. Saulnier-Blache. 
2017. Increased urine acylcarnitines in diabetic ApoE-/- mice: Hydroxytetradecadienoylcarnitine $(\mathrm{C} 14: 2-\mathrm{OH})$ reflects diabetic nephropathy in a context of hyperlipidemia. Biochem. Biophys. Res. Commun. 487:109-115. https://doi.org/10.1016/j.bbrc.2017 .04 .026 .

Nadiv, O., M. Shinitzky, H. Manu, D. Hecht, C. T. Roberts Jr., D. LeRoith, and Y. Zick. 1994. Elevated protein tyrosine phosphatase activity and increased membrane viscosity are associated with impaired activation of the insulin receptor kinase in old rats. Biochem. J. 298:443-450. https://doi.org/10.1042/bj2980443.

Osowska, S., T. Duchemann, S. Walrand, A. Paillard, Y. Boirie, L. Cynober, and C. Moinard. 2006. Citrulline modulates muscle protein metabolism in old malnourished rats. Am. J. Physiol. Endocrinol. Metab. 291:E582-E586. https://doi.org/10.1152/ajpendo .00398 .2005 .

Pan, D. A., S. Lillioja, M. R. Milner, A. D. Kriketos, L. A. Baur, C. Bogardus, and L. H. Storlien. 1995. Skeletal muscle membrane lipid composition is related to adiposity and insulin action. J. Clin. Invest. 96:2802-2808. https://doi.org/10.1172/JCI118350.

Pietiläinen, K. H., M. Sysi-Aho, A. Rissanen, T. Seppänen-Laakso, H. Yki-Järvinen, J. Kaprio, and M. Orešič. 2007. Acquired obesity is associated with changes in the serum lipidomic profile independent of genetic effects-A monozygotic twin study. PLoS One 2:e218. https://doi.org/10.1371/journal.pone.0000218.

Pilch, P. F., P. A. Thompson, and M. P. Czech. 1980. Coordinate modulation of D-glucose transport activity and bilayer fluidity in plasma membranes derived from control and insulin-treated adipocytes. Proc. Natl. Acad. Sci. USA 77:915-918. https://doi.org/ 10.1073/pnas.77.2.915.

Roche, J. R., and D. P. Berry. 2006. Periparturient climatic, animal, and management factors influencing the incidence of milk fever in grazing systems. J. Dairy Sci. 89:2775-2783. https://doi.org/10 .3168/jds.S0022-0302(06)72354-2.

Roche, J. R., D. P. Berry, J. M. Lee, K. A. Macdonald, and R. C. Boston. 2007a. Describing the body condition score change between successive calvings: A novel strategy generalizable to diverse cohorts. J. Dairy Sci. 90:4378-4396. https://doi.org/10.3168/jds 2006-729.

Roche, J. R., D. Blache, J. K. Kay, D. R. Miller, A. J. Sheahan, and D. W. Miller. 2008. Neuroendocrine and physiological regulation of intake, with particular reference to domesticated ruminant animals. Nutr. Res. Rev. 21:207-234. https://doi.org/10.1017/ S0954422408138744.

Roche, J. R., J. M. Lee, K. A. Macdonald, and D. P. Berry. 2007b. Relationships among body condition score, body weight, and milk production variables in pasture-based dairy cows. J. Dairy Sci. 90:3802-3815. https://doi.org/10.3168/jds.2006-740.

Romero, M. J., D. H. Platt, R. B. Caldwell, and R. W. Caldwell. 2006. Therapeutic use of citrulline in cardiovascular disease. Cardiovasc. Drug Rev. 24:275-290. https://doi.org/10.1111/j.1527-3466.2006 .00275.x.

Schuh, K., H. Sadri, S. Häussler, L. A. Webb, C. Urh, M. Wagner, C. Koch, J. Frahm, S. Dänicke, G. Dusel, and H. Sauerwein. 2019. Comparison of performance and metabolism from late pregnancy to early lactation in dairy cows with elevated v. normal body condition at dry-off. Animal 13:1478-1488. https://doi.org/10.1017/ S1751731118003385.

Slotte, J. P. 2013. Biological functions of sphingomyelins. Prog. Lipid Res. 52:424-437. https://doi.org/10.1016/j.plipres.2013.05.001.

Sun, H. Z., K. Shi, X. H. Wu, M. Y. Xue, Z. H. Wei, J. X. Liu, and H. Y. Liu. 2017. Lactation-related metabolic mechanism investigated based on mammary gland metabolomics and 4 biofluids' metabolomics relationships in dairy cows. BMC Genomics 18:936. https:/ /doi.org/10.1186/s12864-017-4314-1.

Suzuki, O., Y. Katsumata, and M. Oya. 1980. Short communication: Oxidation of p-phenylethylamine by both types of monoamine oxidase: Examination of enzymes in brain and liver mitochondria of eight species. J. Neurochem. 3-5:1298-1301.
Takagi, A. 1971. Lipid composition of sarcoplasmic reticulum of human skeletal muscle. Biochim. Biophys. Acta 248:12-20. https:// doi.org/10.1016/0005-2760(71)90069-5.

van den Berg, R. A., H. C. J. Hoefsloot, J. A. Westerhuis, A. K. Smilde, and M. J. van der Werf. 2006. Centering, scaling, and transformations: Improving the biological information content of metabolomics data. BMC Genomics 7:142. https://doi.org/10 $.1186 / 1471-2164-7-142$.

van der Veen, J. N., J. P. Kennelly, S. Wan, J. E. Vance, D. E. Vance, and R. L. Jacobs. 2017. The critical role of phosphatidylcholine and phosphatidylethanolamine metabolism in health and disease. Biochim. Biophys. Acta Biomembr. 1859:1558-1572. https://doi .org/10.1016/j.bbamem.2017.04.006.

Vessby, B., S. Tengblad, and H. Lithell. 1994. Insulin sensitivity is related to the fatty acid composition of serum lipids and skeletal muscle phospholipids in 70-year-old men. Diabetologia 37:10441050. https://doi.org/10.1007/BF00400468.

Vogt, W. 1995. Oxidation of methionine residues in proteins: Tools, targets, and reversal. Free Radic. Biol. Med. 18:93-105. https:// doi.org/10.1016/0891-5849(94)00158-G.

Wang, T. J., D. Ngo, N. Psychogios, A. Dejam, M. G. Larson, R. S. Vasan, A. Ghorbani, J. O'Sullivan, S. Cheng, E. P. Rhee, S. Sinha, E. McCabe, C. S. Fox, C. J. O'Donnell, J. E. Ho, J. C. Florez, M. Magnusson, K. A. Pierce, A. L. Souza, Y. Yu, C. Carter, P. E. Light, O. Melander, C. B. Clish, and R. E. Gerszten. 2013. 2-Aminoadipic acid is a biomarker for diabetes risk. J. Clin. Invest. 123:4309-4317. https://doi.org/10.1172/JCI64801.

Wijekoon, E. P., C. Skinner, M. E. Brosnan, and J. T. Brosnan. 2004. Amino acid metabolism in the Zucker diabetic fatty rat: Effects of insulin resistance and of type 2 diabetes. Can. J. Physiol. Pharmacol. 82:506-514. https://doi.org/10.1139/y04-067.

Wolf, M., S. Chen, X. Zhao, M. Scheler, M. Irmler, H. Staiger, J. Beckers, M. H. de Angelis, A. Fritsche, H. U. Häring, E. D. Schleicher, G. Xu, R. Lehmann, and C. Weigert. 2013. Production and release of acylcarnitines by primary myotubes reflect the differences in fasting fat oxidation of the donors. J. Clin. Endocrinol. Metab. 98:E1137-E1142. https://doi.org/10.1210/jc.2012-3976.

Yang, Y., H. Sadri, C. Prehn, J. Adamski, J. Rehage, S. Danicke, B. Saremi, and H. Sauerwein. 2019. Acylcarnitine profiles in serum and muscle of dairy cows receiving conjugated linoleic acids or a control fat supplement during early lactation. J. Dairy Sci. 102:754-767. https://doi.org/10.3168/jds.2018-14685.

Zandkarimi, F., J. Vanegas, X. Fern, C. S. Maier, and G. Bobe. 2018. Metabotypes with elevated protein and lipid catabolism and inflammation precede clinical mastitis in prepartal transition dairy cows. J. Dairy Sci. 101:5531-5548. https://doi.org/10.3168/jds .2017-13977.

Zeitoun-Ghandour, S., O. I. Leszczyszyn, C. A. Blindauer, F. M. Geier, J. G. Bundy, and S. R. Stürzenbaum. 2011. C. elegans metallothioneins: Response to and defence against ROS toxicity. Mol. Biosyst. 7:2397-2406. https://doi.org/10.1039/c1mb05114h.

Zhang, G., Q. Deng, R. Mandal, D. S. Wishart, and B. N. Ametaj. 2017b. Metabolomics-based profiling identifies serum signatures that predict the risk of metritis in transition dairy cows. J. Anim. Sci. 95(suppl_4):168. https://doi.org/10.2527/asasann.2017.340.

Zhang, G., Q. L. Deng, R. Mandal, D. S. Wishart, and B. N. Ametaj. 2017a. DI/LC-MS/MS-based metabolic profiling for identification of early predictive serum biomarkers of metritis in transition dairy cows. J. Agric. Food Chem. 65:8510-8521. https://doi.org/ 10.1021/acs.jafc.7b02000.

Zukunft, S., C. Prehn, C. Rohring, G. Moller, M. Hrabe de Angelis, J. Adamski, and J. Tokarz. 2018. High-throughput extraction and quantification method for targeted metabolomics in murine tissues. Metabolomics 14:18. https://doi.org/10.1007/s11306-017 $-1312-\mathrm{x}$.

Zukunft, S., M. Sorgenfrei, C. Prehn, G. Moller, and J. Adamski. 2013. Targeted metabolomics of dried blood spot extracts. Chromatographia 76:1295-1305. https://doi.org/10.1007/s10337-013-2429-3. 